\title{
A Complexidade no Fenômeno do Conflito
}

\section{Complexity in the Conflict Phenomenon}

Katia Denise Moreira ${ }^{1}$, Luci Mari Aparecida Rodrigues ${ }^{1} e$ Alexandre Marino Costa ${ }^{1}$

${ }^{1}$ Universidade Federal de Santa Catarina, UFSC 


\title{
Resumo
}

Considerado o pressuposto de que o fenômeno do conflito apresenta bases epistemológicas distintas, com vertentes que ou o refutam ou o consideram essencial para a evolução humana, e, ainda, que essa questão paradoxal se alinha às concepções da teoria da complexidade, este estudo tem por objetivo analisar, a partir de bases epistemológicas, a associação entre o fenômeno do conflito e o paradigma da complexidade. Nessa direção, buscou-se o alinhamento entre os elementos estruturantes de uma e outra teoria; ação que permitiu alcançar como resultado a concepção de que o conflito tem natureza complexa devido a sua dinamicidade, não linearidade, ambiguidade, reconstrutivismo, dialogicidade evolutiva, irreversibilidade e intensidade. Concluiu-se que o fenômeno é considerado essencial quando consolidado como elemento contrário à estagnação e, consequentemente, promotor da evolução.

Palavras-chave: epistemologia, paradigma, conflito, complexidade

\begin{abstract}
Considering the assumption that the conflict phenomenon presents different epistemological bases, with aspects that either, refute or consider it essential for human evolution, and yet, that this paradoxical question is related with the conceptions of complexity theory, this study aims to analyze, from epistemological bases, the association between the conflict phenomenon and the complexity paradigm. In this way, the approach between the structuring elements among theories, allowed to reach as a result, the conception that the conflict has a complex nature, due to its dynamicity, nonlinearity, ambiguity, reconstructivism, evolutionary dialogicity, irreversibility and intensity. In addition, the phenomenon is considered essential when consolidated as an element against stagnation and, so, promoter of evolution.
\end{abstract}

Keywords: epistemology, paradigm, conflict, complexity 
A princípio é importante lembrar que a ciência não é uma estrutura dogmática, ela permite contradições, dúvidas e reflexões (Morin \& Le Moigne, 1999; Serva, Dias \& Alperstedt 2010; Faria, 2012). A ciência, como parte do conhecimento, assume uma postura dinâmica e, nesse sentido, está em oposição àquilo que defendiam os cientistas anglo-saxônicos das décadas de 1950 e 1960, que tentavam inclusive axiomatizá-la (Morin, 1996). Desta forma, diz-se que o conhecimento, ao longo da história, foi adquirindo características específicas, as quais estavam relacionadas com o momento social em que se vivia (Japiassu, 1991).

Todavia, em termos epistemológicos a complexidade não ganhou grande destaque, fato que a deixou à margem daquilo posto como filosofia da ciência (Morin, 1996). Entretanto, há de se considerar que a epistemologia não tem natureza rigorosa ou única e, como tem caráter interdisciplinar, permite ao pesquisador construções sobre sua própria disciplina (Morin \& Le Moigne, 1999; Serva et al. Faria, 2012).

Nessa direção acredita-se que a complexidade em termos epistemológicos pode ser considerada um paradigma, o qual emerge da tentativa de superação de impasses conceituais criados durante seus próprios períodos de desenvolvimento, tanto no que diz respeito à lógica, quanto à própria epistemologia (Serva, 1992). Ainda, sobre a complexidade, trata-se de um fenômeno relacionado aos conceitos de ordem e desordem, que, mesmo paradoxais, são essenciais para a teoria complexa, visto os processos de transformação das ciências ocorridos desde meados do século XVIII, ancorados na oposição ao antigo determinismo (Morin, 1982).

Associa-se a essa concepção, principalmente naquilo que se refere à ideia de confronto, o fenômeno do conflito, o qual traz em sua concepção a posição de elemento opositor à estagnação, uma vez que está alinhado a ações dinâmicas, que funcionam como mola propulsora para mudanças, sejam elas no campo científico, político, econômico ou social (Fiorelli et al., Fiorelli \& Malhadas Júnior 2008). Adicionalmente, no que se refere ao âmbito das organizações, McKibben (2017) expõe que o conflito, utilizado positivamente, pode também estimular e encorajar a mudança, quando o trabalho das equipes se torna estagnado, com possibilidades de se aumentar a produtividade e inspirar o pensamento crítico. Logicamente, na visão dos autores citados presume-se ser necessário administrar situações conflituosas, não no sentido de eliminá-las, conforme tratam os estruturalistas, mas sim de transformá-las, alicerçando-se naquilo que defende o construtivismo.

Além disso, para Gallo (2013), o conflito constitui-se em um tipo especial de sistema complexo, o qual é proveniente de elementos diferentes e que, por vezes, não estão relacionados; conta, ainda, com estruturas adaptativas e mecanismos evolutivos. Nessa perspectiva, para uma compreensão aprofundada do fenômeno, é necessária uma abordagem sistêmica, aliada à utilização de disciplinas sociais e científicas, de maneira que se afasta de raciocínios lineares e fragmentados.

Dessa maneira, ao se considerar que o conflito apresenta bases epistemológicas distintas, tanto associadas a vertentes paradigmáticas que o refutam, sob o argumento de que a ordem deve prevalecer, quanto àquelas que o reconhecem como essencial e, relacionada a essa concepção, a ideia da desordem (todavia, corretamente administrada com o intuito de estabelecer um processo de mudança) e com base no pressuposto de que o 
conflito tem vínculos com o paradigma da complexidade, este estudo tem por objetivo analisar a complexidade no fenômeno do conflito.

O estudo se justifica pela importância em se refletir sobre um fenômeno cujo conceito ainda permeia a antítese do bem e do mal no âmbito organizacional. Em outras palavras, acredita-se ser relevante e também oportuno tratar de um elemento paradoxal, ou seja, ao mesmo tempo em que desconstrói um contexto é essencial para reconstruí-lo. Ademais, constatou-se na revisão da literatura que os temas conflito e complexidade ainda são tratados de maneira incipiente e separada na literatura, embora suas implicações para as organizações sejam factíveis e complementares. Ou seja, é necessário tratá-los sob uma perspectiva dialógica para que se avance o pensamento organizacional.

No que se refere à estrutura, este estudo inicia com esta seção introdutória, na qual se apresenta o tema problema, objetivos e justificativa; em seguida tem-se o escopo teórico que fundamenta o ensaio, cujas matérias abordadas tratam da relação entre epistemologia e paradigmas sociais e associadas e esses dois elementos primeiros, a complexidade e o fenômeno do conflito. Na sequência são apresentados os procedimentos metodológicos e a discussão que trata da aproximação entre o conflito e a complexidade e, em um último momento, externam-se as considerações finais, seguidas das referências.

\section{O Paradigma da Complexidade}

Naquilo que se refere às origens da complexidade, conforme já exposto, não foi um fenômeno que emergiu na epistemologia, visto a tendência da corrente anglo-saxônica (1950-1960) da ciência ter características demarcadas naquilo que se referia à certeza da ciência (Morin, 2002). Todavia, o filósofo Gaston Bachelard (18841962) tratou da complexidade, sem, entretanto, alcançar sucesso com sua teoria (Morin, 1996).

Tempos depois, a complexidade é associada às ciências exatas e biológicas. Sobre tal afirmação, Serva (1992) explica que o paradigma da complexidade encontra sucesso quando associado às pesquisas realizadas no Biological Computer Laboratory, pelo biofísico austríaco Heinz Von Foerster (1911-2002), na Universidade de Illinois, em 1956. Ademais, a complexidade, em conjunto com a física, a química e a termodinâmica, alinhadas à matemática, ancorou as considerações sobre a capacidade da matéria de auto-organização, a partir de movimentos espontâneos (Serva, 1992).

Nessa direção, Morin (2011) apresentou a correlação entre a complexidade e a cibernética e sobre tal vínculo afirmou que foi por meio dele que a complexidade, relacionada ao fenômeno de auto-organização, inseriuse na ciência, alicerçada, ainda, nos estudos do matemático húngaro John Von Neumann (1903-1957). Para Morin (2011), o desenvolvimento da complexidade como um paradigma se deu propriamente no século XIX, em um movimento de reação ao determinismo, que se firmava em teóricos desde René Descartes (1596-1650) a Isaac Newton (1643-1727).

Considerado o paradigma da complexidade como uma oposição ao mecanicismo determinista, Morin (2011) questionou sobre o que seria a complexidade e respondeu por meio de dois direcionamentos: a) a complexidade é um tecido (complexus: o que é tecido junto) de constituintes heterogêneas, associadas e inseparáveis: um 
paradoxo do uno e do múltiplo; e b) a complexidade é efetivamente o tecido de acontecimentos, ações, interações, retroações, determinações e acasos que constituem o mundo fenomênico.

Morin (2011) destaca que a complexidade acontece no contexto das relações humanas, principalmente quando o sujeito está inserido em um evento antagônico, momento em que exerce seu papel de forma "natural". Vale dizer que as considerações de Morin (2011) têm sustentação empírica, observada na sociedade da época, por meio do descrito nos romances do século XIX e início do século XX. Naquele período, ao mesmo tempo em que a ciência tenta eliminar o que é individual e singular, para só reter leis gerais - determinismo, autores como Balzac (1799-1850), na França, e Dickens (1812-1870), na Inglaterra, encontram no romance uma forma de expor o contraditório, por meio de personagens sui generis, peculiares, que refutaram, de certa forma, a normas sociais de seu tempo.

Cabe adicionar, no que se refere à complexidade, que anteriormente Morin (1996) a associou à questão da ordem e da desordem, ao dizer que o fenômeno apresenta traços inquietantes do emaranhado, do inextricável, da desordem, da ambiguidade, da incerteza, mas que, no entanto, o conhecimento precisa de ordem, visto que pretende afastar aquilo que é incerto, a partir de objetivos como clarificar, distinguir, dar certeza, precisar. A essa posição estruturalista/funcionalista que o conhecimento tende a recorrer por pânico ou por ser esse o caminho conhecido, Morin (2011) adverte que "tais operações, necessárias à inteligibilidade, correm o risco de provocar a cegueira, se elas eliminam os outros aspectos do complexus; e efetivamente, como eu o indiquei, elas nos deixaram cegos" (pp. 13-14).

Nessa direção, Demo (2008, p. 13), baseado em Holland (1995), explica que a complexidade remete à ideia de algo caótico e estruturado: "é caótico no sentido de que seu ser se apresenta dotado de propriedades não lineares ou de dinâmica também ambígua/ambivalente. É estruturado porque, na maior desordem, sempre é possível divisar alguma ordem". Tal afirmativa vai na direção do que já havia sido exposto por Morin (1982), quando alertou sobre a necessidade de considerar que por trás da ordem e da organização sempre existe a desordem, a qual é assinalada pelas incertezas.

Isso significa dizer que a organização não pode ser reduzida à ordem, apesar de comportá-la e produzila. Isto é, o cerne do conflito está naquilo que caracteriza a complexidade, por um lado a desordem coopera na geração da ordem organizacional, por outro ela ameaça à ordem com a desintegração, seja por fatores externos ou internos (Serva et al., 2010, p. 282). Alicerçado pela teoria de Morin (1982), Demo (2008) caracteriza a complexidade ao apontar e explicar uma série de elementos que a justificam, conforme ilustra a Figura 1. 
Figura 1

Características da complexidade - Demo (2008)

Características da complexidade

Elemento estruturante

Descrição

Princípio do pensamento complexo

Dinâmica

Não linear

Irreversível

Intensidade

Ambiguidade/ambivalência
Não pode ser dinâmico o que não for campo de

Recursão

forças contrárias.

A não linearidade implica equilíbrio em

desequilíbrio, já que a segurança de algo

fechado coincide com a morte. Para continuar

existindo, é mister mudar, não apenas mudar

linearmente, de modo tranquilo, previsível,

controlável, mas criativo, surpreendente,

arriscado.

A complexidade não é propriamente reprodutiva

ou replicativa, ou apenas recorrente. Em seu

processo de ser, a complexidade permanece a

mesma, mudando sempre.

Processo dialético evolutivo

Quando aventamos que fenômenos complexos

podem aprender, insinuamos apenas que seus

processos podem incluir criatividade autêntica

no sentido de que produzem modo de ser que é

sempre também de vir a ser.

Refere-se, num primeiro passo, à inserção temporal:

com o passar do tempo, nada se repete, por

mais que possa parecer; qualquer depois é

diferente do antes, não se pode tomar como

equação linear entre antes e depois, mas como

não linear.

Busca ir além de indicadores empíricos mensuráveis,

busca diretamente dimensões de maior

profundidade

Refere-se à estrutura, no sentido da composição

também desencontrada de seus componentes,

típica da "unidade de contrários".
Hologramático

Recursão

Dialógico

Recursão

Recursão

Hologramático

Nota. Construção dos autores com base em Morin e Le Moigne (1999) e Demo (2008).

É salutar observar que as características apresentadas na Figura 1 encontram alicerce nos princípios do pensamento complexo de Morin e Le Moigne (1999), dispostos na terceira coluna: a) o dialógico: que une princípios ou noções antagônicas, que, ao invés de se repelir, são indissociáveis e indispensáveis para a compreensão de uma 
mesma realidade; b) da recursão: trata-se de um círculo gerador, no qual tanto os produtos como seus efeitos são eles próprios geradores e causadores daquilo que se produz; e c) hologramático: evidencia a questão que não somente a parte está no todo, mas que o todo está na parte.

Observa-se que a complexidade, por suas características, vai ao encontro daquilo que defendem os opositores do enquadramento paradigmático e, nesse sentido, associa-se ao conflito, que é um fenômeno também contrário a enquadramentos, visto sua natureza e essência. Na sequência, reflete-se sobre o fenômeno do conflito e sua posição epistemológica e paradigmática.

\section{O Fenômeno do Conflito}

A partir dos apontamentos sobre epistemologia e paradigmas, pretende-se, por meio das concepções teóricas que os definem, associá-los ao fenômeno do conflito seja de forma a refutá-lo em favor do regramento, seja na posição de reconhecê-lo como elemento essencial para evolução. Nessa direção, acredita-se ser importante, primeiro, dizer que divergências podem acontecer por vários motivos e estão sempre inseridas em um contexto, seja ele familiar, social ou profissional, e, também, que as diversidades ideológicas são vivenciadas desde os primórdios da humanidade e se acredita que são elementos contribuintes para a evolução histórica. Acerca de tal afirmação, Moore (1998) comenta que "Desde o início da história registrada, temos evidência de disputas entre cônjuges, filhos, pais e filhos, vizinhos, grupos étnicos e raciais, colegas de trabalho, superiores e subordinados, organizações, comunidades, cidadãos e seu governo e nações" (p. 19).

Alinhado ao posto por Moore (1998) está o expresso por Ramos (1989): “O homem tem diferentes tipos de necessidades, cuja satisfação requer múltiplos tipos de cenários" (p. 136). Isso significa dizer que os antagonismos têm origem na satisfação das vontades e desejos individuais que, quando inseridos em um grupo heterogêneo, têm como consequência o conflito. Contudo, “O conflito precisa ser percebido pelas partes envolvidas; a existência ou não do conflito é uma questão de percepção. Se ninguém tiver noção da existência do conflito, há um acordo geral de que ele não existe" (Robbins, 2005, p. 236).

Uma vez evidenciado o conflito, duas são as linhas distintas que o caracterizam em termos de conceitualização. Uma que o considera como algo negativo - funcionalismo/estruturalismo - e, assim sendo, precisa ser evitado. Outra, oposta e embasada na dialética, o entende como elemento necessário para a evolução. Sobre tais dimensões, Wisinski (1995) explica que no passado o conflito foi “associado a comportamento indesejável, era visto como uma característica de indivíduos que não conseguiam se relacionar com os outros, que não faziam parte da equipe ou, simplesmente, não se encaixavam. A melhor maneira de lidar com o conflito era evitá-lo" (p. 1). Por outro lado, ainda, segundo o autor, contemporaneamente o conflito é compreendido de forma diversa, como algo normal e natural; ademais, é tratado como uma forma de dinâmica interpessoal e quando gerido de modo correto pode ser administrado ou, muitas vezes, resolvido. Sob esse ângulo possivelmente resultarão ações criativas.

Moscovici (1997) complementa a teoria de Wisinski (1995), naquilo que se refere ao seu caráter positivo, quando aponta que o conflito em uma lógica mais ampla tem funções positivas, visto que previne a estagnação consequente do equilíbrio constante dos atos de concordância, estimula o interesse, a curiosidade e descobre 
problemas que demandam solução. O conflito, para a autora, é elemento fonte de mudanças pessoais, grupais e sociais. Tais conceitos, traduzidos para as escolas da administração, têm, de acordo com Robbins (2005), a configuração descrita na Figura 2.

Figura 2

As escolas do pensamento e a visão sobre o conflito

Escolas da administração

Visão do conflito

Escola clássica/visão tradicional

O conflito deve ser evitado: ele seria a indicação de que alguma coisa não está funcionando direito dentro do grupo.

Escola das relações humanas

Argumenta que o conflito é uma consequência natural e inevitável em qualquer grupo, não sendo necessariamente ruim, podendo mesmo ter o potencial de ser uma força positiva na determinação do desempenho do grupo.

Escola interacionista Perspectiva mais recente, que propõe não apenas que o conflito pode ser uma força positiva, como defende abertamente a tese de que um mínimo de conflito é absolutamente necessário para o desempenho eficaz de um grupo.

Nota. Elaborado pelas autoras, com base em Robbins (2005).

Diante do posto na Figura 2, visualiza-se a variação de concepção na conceitualização do fenômeno do conflito tratada por Wisinski (1995). De forma circunstanciada, tem-se inerente à primeira escola a definição de Likert e Likert (1980), que consideram o conflito como a luta ativa por resultados desejáveis para uma parte. Em outras palavras, quando o resultado é favorável para um sujeito/organização, consequentemente, é desfavorável para outros, fato que, se supõe, gera disfuncionalidades à situação. A segunda escola, da linha teórica das Relações Humanas, associa-se à reflexão de Moore (1998), "sobre a percepção de o conflito se fazer presente em todos os relacionamentos humanos, seja qual for a sociedade" (p. 19). Ou seja, o autor considera que o fenômeno deve ser aceito como algo natural e, dentro do possível, administrado de forma contributiva para com a evolução das partes envolvidas.

As acepções da escola interacionista podem ser observadas naquilo que dissertam Fiorelli, Fiorelli e Malhadas Junior (2008), quando definem que “O conflito opõe-se à estagnação. Desempenha o papel de mola propulsora que permite à humanidade sobreviver em um planeta de recursos limitados" (p. 6). Assim, brevemente, definido e caracterizado o conflito, retoma-se a questão epistemológica. Importante lembrar que, por ora, trabalhase com a proposição de que o conflito é um fenômeno presente em todos os paradigmas, uma vez que sempre houve contradições de ideais entre os teóricos e mesmo as grandes mudanças paradigmáticas, se bem observado, se deram por discordâncias.

Assim, denota-se de forma bastante breve que nos estudos sobre o racionalismo, empirismo, utilitarismo, positivismo, funcionalismo e teoria dos sistemas, paradigmas mais rígidos, associados às escolas clássica e científica, o conflito era algo não existente ou que deveria ser eliminado. O racionalismo e o empirismo determinavam que o conhecimento só era considerado como tal por meio da experiência. Um exemplo disso é o método extremamente 
rígido apresentado por René Descartes (1979), que não admitia adotar outros caminhos, senão aqueles postos por seu método.

No utilitarismo, sinteticamente, havia apenas duas possibilidades: a dor e o prazer, ou um ou outro, sem outras possibilidades. No positivismo, com Auguste Comte (1798-1857), entre outros, em resumo, somente o empirismo era admitido como critério de verdade na construção do conhecimento. Talvez, nesses casos, o conflito estivesse presente na transição para o neopositivismo, quando Popper (1980) propôs a falseabilidade como critério de demarcação científica, ou seja, havia certo conflito, uma vez que a ciência poderia produzir teorias falseáveis, capazes de serem validadas enquanto não fossem refutadas. Nesse contexto, o conflito era fator positivo, no sentido da tendência para a evolução da teoria em questão; no entanto, não era algo "bem-vindo".

Para o funcionalismo e teoria dos sistemas, em síntese, o conflito precisava ser evitado, uma vez que a sociedade deveria funcionar como um sistema, mantendo-se sempre o equilíbrio. Para Parsons (1967) e sua teoria funcionalista estrutural, as mudanças e, principalmente, o conflito eram considerados anormais e disfuncionais (Rahim, 2010). Respeitando a posição dos funcionalistas e tendo como entendimento que o que se propõe no funcionalismo é a concepção de pensar as instituições sociais, a partir de sua funcionalidade, dois fatos são passíveis de reflexão: o primeiro é que se o fato social é coercitivo e, sendo assim, não é possível que o indivíduo tenha a possibilidade de mudá-lo, ou seja, se a sociedade é formada pela ação de cada sujeito, esse sujeito precisa conformar-se com aquilo que lhe é imposto. Entende-se que, contemporaneamente, apesar de a sociedade ainda ser estruturada por regras, mesmo porque, caso contrário o caos se instalaria, essa "determinação" esteja mais abrandada.

Em relação ao segundo, acredita-se ser impossível concordar com a posição de que os conflitos não devem existir, uma vez que, se tal proposição fosse imposta, a sociedade estaria fadada à estagnação. Em concordância a tal raciocínio está o posto por Rahim (2010), quando explica que o conflito, em certa medida, é promotor da criatividade e, sem dúvida, é o precursor da evolução.

Ao refletir sobre as questões da contradição, Hegel (1970-1831) considera que esse fenômeno conduz o movimento e impulsiona a atividade (Foulquié, 1949). Interessante retomar a respeito das concepções de Hegel (1970-1831), naquilo que trata da conciliação dos contrários e do processo dialético, ambos divididos em três momentos, sob os quais se faz uma breve proposição sobre a tese, a antítese e a síntese do conflito, visto que esse é o elemento foco deste trabalho. Assim, acredita-se ser possível estabelecer: a) tese: o conflito existe e causa mudança; b) antítese: o conflito não deveria existir porque causa desequilíbrio; e c) síntese: se o conflito não causar desequilíbrio, não haverá mudança.

Diante do discutido, entende-se que a aplicação da dialética e da teoria crítica nas organizações configura-se como um elemento diferenciador, uma vez que busca o movimento da gestão. Ou seja, a totalidade organizacional é analisada por meio dos processos históricos, das relações sociais e humanas e das características individuais existentes, não só superficialmente, mas naquilo que está sob o aparente. Dessa maneira, na dialética e na teoria crítica os conflitos não são elimináveis, em outras palavras, compreende-se que situações contraditórias 
são reais, fazem parte das relações humanas e, sendo assim, precisam ser teorizadas. Nessa direção, Demo (1985) explica que o conflito foi fenômeno muito impugnado em termos de orientação teórica e chama a atenção para a orientação dialética que admite "que toda formação social contém contradições internas suficientes para ser historicamente superável. A situação predominantemente conflituosa da realidade social pertence à sua condição de normalidade histórica" (p. 150).

No que se refere ao construtivismo, em resumo, o conflito é compreendido de forma oposta àquela do paradigma positivista. As características construtivistas se voltam para o conhecimento, alinhado ao caráter criativo, direcionado para a apreensão de uma realidade complexa, em que o sujeito, ao mesmo tempo em que busca conhecê-la, a constrói, a interpreta e a cria, inserindo-se em um processo no qual recria a si mesmo (Grisales, 2011). Nessa perspectiva, o construtivismo está intimamente ligado àquilo que propõe a gestão de conflitos diferenciada, na qual a presença de divergências é essencial para um processo de movimentação, em oposição à estagnação. Em seguida, passa-se aos métodos adotados no estudo.

\section{Procedimentos Metodológicos}

A fim de alcançar o objetivo deste trabalho, ou seja, analisar a partir de bases epistemológicas a associação entre o fenômeno do conflito e o paradigma da complexidade, fez-se uso de uma combinação de procedimentos metodológicos, os quais foram estabelecidos no intuito de informar os caminhos percorridos nesta pesquisa (Gerhardt \& Silveira, 2009). Dessa maneira, naquilo que se refere à natureza, este é um estudo básico, que busca expandir o conhecimento a partir de princípios universais e que têm significância para a sociedade (Saunders, Lewis \& Thornhill, 2009). Nessa direção, estuda-se o conflito, ancorado em bases epistemológicas, e sua aproximação com o paradigma da complexidade, visto ser, o primeiro, um fenômeno influenciador das transformações sociais envoltas por situações complexas.

Quanto aos objetivos, o estudo é descritivo, uma vez que busca retratar uma situação sobre a qual se tem uma imagem clara dos fenômenos sobre os quais se deseja refletir (Saunders et al., 2009). Nesta pesquisa, os fenômenos descritos são o da complexidade e o do conflito, a partir de suas origens epistemológicas e posicionamento paradigmático.

Em relação à abordagem, foi utilizada a qualitativa, a qual, de acordo com Creswell (2009), abarca a compreensão do significado de um fenômeno, acerca de uma situação em que ele se insere e, ainda, a partir da interpretação do pesquisador frente à relevância em se considerar a complexidade dessa circunstância. Assim, não se intencionam quantificações, mas sim a construção de uma dada realidade (Triviños, 2012). Desse modo, o que se objetiva é refletir sobre dois fenômenos (complexidade e conflito), sobre os quais acredita-se haver uma aproximação conceitual, que permite a constituição de concepções de um sobre o outro.

Em referência à estratégia, trata-se de uma pesquisa bibliográfica, realizada com base em um conjunto de conhecimentos sistematizados sobre o tema explorado, que se ancoraram em materiais publicados, como livros e artigos de revistas acadêmicas e de periódicos científicos (Saunders et al., 2009). Nessa direção, realizouse a pesquisa no intuito de encontrar outros estudos que tivessem aproximação com a temática ora verificada. 
Assim, fez-se busca nas bases Web of Science, EBSCOhost e Wiley Online Library, além de publicações em livros clássicos sobre o tema. Os indexadores de dados foram selecionados por conterem publicações inerentes aos estudos da área organizacional e por reunirem material tanto de fontes nacionais como internacionais, além de serem reconhecidamente relevantes para a área em questão. Para a busca não foi definido um recorte temporal específico, porque o foco era conhecer os trabalhos e sua contribuição, além de verificar se havia lacunas sobre o tema.

Encontrou-se que não havia trabalhos que tratassem especificamente da questão epistemológica associada ao conflito e sua inserção no paradigma da complexidade, e sim aproximações relacionadas ao tema. Tais constatações possibilitaram a fundamentação do construto teórico deste estudo, visto que nos materiais houve elementos que indicaram a importância de discussões sobre o tema e a necessidade de ampliá-lo, na conjuntura de sua relevância para a área organizacional.

No que diz respeito ao tratamento dos dados, utilizou-se a análise de conteúdo, que, de acordo com Bardin (2011), contempla diversas propostas de métodos complementares para sua realização, dentre os quais se optou pela categorização; esta busca a classificação de um conjunto constitutivo, formado por elementos selecionados a partir de critérios pré-definidos, e que possuem características comuns. Desse modo, “A categorização tem como primeiro objetivo fornecer, por condensação, uma representação simplificada dos dados brutos" (Bardin, 2011, p. 148). Diante disso, as categorias analíticas deste estudo se materializam nas características da complexidade descritas por Demo (2008), as quais serviram como estrutura para a identificação do conflito como um fenômeno complexo. Na sequência, tem-se a apresentação das discussões e resultados deste estudo.

\section{A Complexidade no Fenômeno do Conflito}

Discutidas as relações entre epistemologia e paradigmas, das quais emergiram as reflexões sobre o paradigma da complexidade e do posicionamento do fenômeno do conflito nessas dimensões, explora-se agora a associação entre o conflito e a complexidade, visto a paradoxalidade que envolve o primeiro. Em outras palavras, o fenômeno, ao mesmo tempo em que desconstrói um determinado contexto, é essencial para sua reconstrução/ evolução.

Nesse sentido, resgata-se que os conflitos estão presentes "em todos os tipos de relacionamentos, na família, no emprego, no social, no lazer; ao longo da vida, aumentam em quantidade e tornam-se mais complexos, notadamente na fase adulta" (Fiorelli et al., 2008, p. 5), ou seja, na medida em que o ser humano evolui, tanto pessoal quanto profissionalmente, crescem também os conflitos que envolvem as relações entre ele consigo, bem como entre ele e a sociedade. Ademais, Fernandes Neto (2005) aponta que para compreender o enredo de uma situação conflituosa é preciso uma análise pormenorizada do comportamento das partes, que nada mais é do que uma soma de elementos, como, por exemplo, medos, emoções, experiências, crenças, preocupações, autoestima, entre outros, a fim de desvendar os elementos que motivam o conflito.

De acordo com o posto, deduz-se que administrar o conflito é também uma tarefa complexa, uma vez que envolve o trabalho de avaliação do comportamento das partes, suas necessidades e vontades, elementos 
que inegavelmente são dinâmicos, ambíguos e não lineares. Tais características configuram o chamado caos estruturado, apontado por Demo (2008) em suas discussões acerca da complexidade. Boulding (1962) já expressava que os seres humanos são movidos não apenas por pressões, mas também por objetivos, que inclusive são suscetíveis a mudanças. No entanto, há certa constância nas vontades humanas, a qual permite uma estabilidade em termos gerais do sistema. Ou seja, os indivíduos são dinâmicos e ambíguos.

Sampaio e Braga Neto (2017), em outra perspectiva sobre a associação entre o conflito e a complexidade, lembram que há um movimento natural, de aumento da complexidade do conflito ao longo da vida do sujeito, decorrente das relações interpessoais, acentuada por contextos cada vez mais complexos; aumento das interrelações em rede, devido às inúmeras possibilidades de ofertas; diversidade de conjunturas e aumento da conscientização sobre os direitos individuais e coletivos. A concepção dos autores relaciona-se ao discutido por Morin (2011) sobre buscar a complexidade em circunstâncias nas quais ela parece ser ausente, como, por exemplo, na vida cotidiana.

Em sentido complementar traz-se o argumentado por Rocheblave-Spenlé (1974), quando evidencia que o conflito só existe quando forças confrontantes, com sentido dinâmico (princípio de ação nela própria), interagem reativamente. Observa-se, ainda, que Morin (1982), ao tratar da complexidade, caracteriza também a existência do conflito como um elemento natural das ações humanas. Em outras palavras, o conflito é complexo, uma vez que se assemelha a exatamente aquilo que Morin (1982) comenta sobre o extremismo de ambas as posições, isto é, um universo estritamente determinista/ordenado seria um ambiente sem devir, sem inovação, sem criação; por outro lado, um sistema de completa desordem não teria a capacidade de constituir organização, de conservar a novidade e, consequentemente, não evoluiria.

Considera-se que o exposto aproxima as duas unidades analíticas deste estudo - o conflito e a complexidade -, visto que, no primeiro há presença do segundo e nas características do segundo há indícios do primeiro. Assim, no sentido de condensar a possibilidade de associação entre a complexidade e o conflito, a Figura 3 apresenta o alinhamento entre o que se refere às características da complexidade e aos elementos que definem uma situação de conflito. 


\section{Figura 3}

Comparação entre as características da complexidade e conceitos de conflito.

Características complexidade

Demo (2008)
Descrição da característica

Não pode ser dinâmico o que não for campo de forças contrárias.

A não linearidade implica equilíbrio em desequilíbrio, já que a segurança de algo fechado coincide com a morte. Para continuar existindo, é mister mudar, não apenas mudar linearmente, de modo tranquilo, previsível, controlável, mas criativo, surpreendente, arriscado.

Reconstrutiva

Processo dialético evolutivo
A complexidade não é propriamente reprodutiva ou replicativa, ou apenas recorrente. Em seu processo de ser, a complexidade permanece a mesma, mudando sempre.

Quando aventamos que fenômenos complexos podem aprender, insinuamos apenas que seus processos podem incluir criatividade autêntica, no sentido de que produzem modo de ser que são sempre também de vir a ser.
Conceitos que definem uma situação de conflito

Para que haja conflito é preciso, pois, em primeiro lugar, que as forças confrontantes sejam forças com sentido dinâmico, isto é, que contenham em si próprias seu princípio de ação (Rocheblave-Spenlé, 1974, p. 12)..

O conflito previne a estagnação decorrente do equilíbrio constante da concordância, estimula o interesse e a curiosidade pelo desafio da oposição, descobre os problemas e demanda sua resolução (Moscovici, 1997, p. 146).

Do ponto de vista constitutivo, o conflito propicia condições de crescimento e transformação sempre que, por intermédio da flexibilização do desejo, atinge-se a noção de alteridade (Muszkat, 2005, pp. 28-29).

"Além disso, é visto como uma dinâmica interpessoal e, quando tratado de maneira correta, pode ser ao menos administrado, muitas vezes resolvido e, provavelmente, terá resultados bastante criativos" (Wisinski, 1995, p. 1). 
Características complexidade

Demo (2008)

Irreversível

Intensidade

Ambiguidade / ambivalência
Descrição da característica

Conceitos que definem uma situação de

conflito

Refere-se, em um primeiro passo, à

inserção temporal: com o passar do

tempo, nada se repete, por mais que

possa parecer; qualquer depois é

diferente do antes, não se pode tomar

como equação linear entre antes e

depois, mas como não linear.

Busca ir além de indicadores empíricos

mensuráveis, busca diretamente

dimensões de maior profundidade.

Refere-se à estrutura, no sentido da composição também desencontrada de seus componentes, típica da

"unidade de contrários".
Funciona, verdadeiramente, como raiz de mudanças pessoais, grupais e sociais (Moscovici, 1997, p. 146).

O conflito opõe-se à estagnação. Dinâmico. Desempenha o papel de mola propulsora que permite à humanidade sobreviver em um planeta de recursos limitados (Fiorelli et al., 2008, p. 6).

De um ponto de vista mais amplo, o conflito tem muitas funções positivas (Moscovici, 1997, p. 146).

Nota. Elaborado pelas autoras com base em Demo (2008), Fiorelli et al. (2008), Moscovici (1997), Muszkat (2005), RocheblaveSpenlé (1974) e Wisinski (1995).

A Figura 3 ancora-se no teorizado por uma série de autores que tratam o conflito como um fenômeno natural, inerente às relações humanas e como um elemento necessário para a garantia da evolução. Em termos epistemológicos, o teorizado por esses autores insere-se em paradigmas que relacionam o conflito como algo natural ou que deve até ser incentivado como uma ação de oposição à estagnação.

Na caracterização do conflito pela socióloga francesa Rocheblve-Spenlé (1974), observa-se a dinâmica do fenômeno. No texto utilizado para esse estudo, a autora trata o conflito sob o aspecto de forças confrontantes e de oposição, permeadas pela ação. Tal posicionamento assemelha-se àquilo que trata a teoria da complexidade, alinhando-se ao posto por Prigogine e Stengers (1997), quando dissertam sobre as estruturas dissipativas, que, mesmo sendo sustentadas por um arcabouço estruturante, apresentam em sua composição unidades imprevisíveis e incontroláveis, temporalmente marcadas e provenientes de um sistema de criatividade possível e necessário.

Quando Moscovici (1997) diz que o conflito previne a estagnação, verifica-se a semelhança com aquilo que propõe a teoria da complexidade. Inclusive, na questão da não linearidade. Nesse sentido, Demo (2008) diz que é “É preciso ultrapassar a noção de simples organização das partes, para atingir modos de ser: na complexidade não linear pulsa relação própria entre o todo e as partes" (p. 17). Ao se relacionar o dito à questão do conflito, entende-se ser importante analisar uma situação antagônica, a partir da relação entre o objeto de discórdia e as partes e, inclusive, sugere-se que as próprias partes operam tal ação, utilizando, por exemplo, a mediação. Esta, 
de forma sintetizada, significa que um terceiro sujeito, aceitável pelas partes, interfere na negociação do conflito (Moore, 1998). A mediação, segundo o autor, possibilita o estabelecimento ou fortalecimento de relacionamentos de confiança e respeito ou, ainda, caso isso não ocorra, proporciona encerrar a divergência de maneira que sejam minimizados os custos e danos psicológicos.

Relevante apontar que o fenômeno do conflito existe, justamente, porque na natureza, apesar de um mesmo elemento ser a base de um todo, o todo não é propriamente igual (Demo, 2008) e, sendo assim, ao passar por um processo conflituoso o sujeito se reconstrói, transforma-se, logicamente, quando o fenômeno é administrado de forma a proporcionar tal resultado. Nessa acepção, Muszkat (2005) traz a questão da alteridade, que é a capacidade que um sujeito tem de se colocar no lugar do outro, em relações ancoradas pelo diálogo e pela valorização das diferenças. Dito de outro modo, se as partes conflitantes levarem em consideração o sentido da alteridade, o resultado da situação conflituosa "Torna-se, por isso, irreversível: não se pode passar do depois para o antes, nem o depois é igual ao antes" (Demo, 2008, p. 17). Consequentemente, o conflito funciona como ferramenta de mudança, conforme aponta Moscovici (1997); um processo de mudança, consequentemente, gera aprendizado e fomenta a capacidade que o indivíduo tem de se instruir. A essa característica alinha-se o processo dialético evolutivo, que em relação ao conflito está ligado à capacidade que o fenômeno tem de, quando tratado de maneira correta, proporcionar resultados criativos, conforme apontou Wisinski (1995).

Em relação à intensidade, é interessante comentar a metáfora utilizada por Demo (2008) sobre o esvoaçar de uma borboleta não "causar" diretamente um tufão; no entanto, quando a dinamicidade dos movimentos os segmenta para várias direções, provocando outros, diversos e desproporcionais, há certa ligação entre os eventos, isto é, o tufão não é reproduzido a partir do esvoaçar da borboleta, todavia pode ter o esvoaçar da borboleta como uma de suas origens. Nessa lógica, o conflito é intenso porque é dinâmico e se observa que, com a aplicação de um método de resolução adequado, o indivíduo inicia um processo de transformação, tal qual uma mola propulsora (Fiorelli et al., 2008), que permitirá ao sujeito reconstruir suas percepções, reproduzindo, reconstruindo e recriando suas ações.

Na mesma linha de pensamento e considerado o conflito como um processo dialógico, não se pode excluir dele a ambiguidade/ambivalência. Quando Moscovici (1997) diz que o conflito, apesar de ser um termo com conotação "negativa", tem muitas funções positivas, a autora transfere ao fenômeno outra significância. Vale destacar que o conflito administrado sob os pressupostos da mediação, por exemplo, favorece o diálogo. Contudo, observa-se que a tendência é, ainda, por aplicar o dispositivo dominante, justiça estatal, na qual o diálogo entre as partes é praticamente inexistente. Nesses termos, Demo (2008) faz referência à inquietude de Habermas (2003), sobre a falta de abertura para ação comunicativa, implícita no diálogo entre os indivíduos, cuja semântica é, de certa forma, indomável.

Ressalta-se que a promoção do diálogo entre as partes, quando na administração de uma situação antagônica, impulsiona o processo de aprendizagem. Tal afirmação alinha-se ao posto por Habermas (2003), que elege o diálogo entre os sujeitos como elemento de aprendizagem reconstrutiva política, não linear, intenso e 
irreversível, que encontra na ambiguidade o componente de sustentação de sua dinâmica aberta. Em concordância com o teórico, acredita-se que o conflito, quando gerido efetivamente, promove a aprendizagem, uma vez que instiga o desenvolvimento pessoal, profissional e social do sujeito.

Por fim, Demo (2008) complementa a questão do conflito, da complexidade e da aprendizagem, quando trata da complexidade de fenômenos como aprender e conhecer. $\mathrm{O}$ autor argumenta que tais ações não se acabam em procedimentos lógicos, recursivos, reversíveis, porém implicam a habilidade de ver mais do que um dado, na manifestação não lógica da lógica, no ausente do que está presente, na mensagem da falta de mensagem, no sentido da falta de sentido, nos duplos significados, e, assim, é também o processo do conflito um componente de um enredo complexo.

\section{Considerações Finais}

A análise da complexidade no fenômeno do conflito embasou as reflexões deste estudo, a partir de um escopo teórico analítico ancorado em bases da sociologia e das ciências da administração. O propósito foi o de identificar se conflito se caracterizava como um fenômeno complexo e, para tanto, buscou-se alinhá-lo a paradigmas ou que o refutassem ou que o reconhecessem como necessário e, na sequência, correlacioná-lo às concepções da complexidade.

Elaborou-se um construto teórico associado a correntes paradigmáticas, fato que tornou possível o alcance do objetivo deste trabalho e da proposição teórica que contemplou a tese, antítese e síntese descrita na seção introdutória sobre o tema. Cabe apontar que a caracterização da complexidade identificada por Demo (2008) proporcionou a construção de categorias de análise que permitiram a comparação entre a teoria dos estudos complexos e o fenômeno do conflito, o que levou à constatação teórica do pressuposto de que o fenômeno é, essencialmente, uma questão complexa.

Tal conclusão se sustenta no resultado das discussões, que demonstraram que o conflito é dinâmico, visto que nele há ação. Esta, por sua vez, é intensa e pode ser considerada uma mola propulsora para o desenvolvimento do sujeito. O fenômeno é, por natureza, não linear e ambíguo, pois do contrário não seria conflito. E, ainda, quando administrado de maneira adequada, a partir de um processo dialético evolutivo é reconstrutivo e irreversível.

A essa última constatação associa-se a questão da mediação de conflitos como ferramenta de gestão no ambiente organizacional e a possibilidade que o método proporciona de construtividade, a partir de situações conflitivas. Consequentemente, tal ação é um desafio para o gestor justamente pela sua complexidade.

Ao final deste estudo acredita-se que o conflito é um fenômeno complexo, visto que ao mesmo tempo em que é caótico, também é estruturado, conforme apontou Demo (2008). Julga-se que o caótico está relacionado às questões da não linearidade, da ambiguidade e, certamente, da dinâmica. É estruturado, porque o conflito, de uma maneira ou outra, precisa ser administrado, pois, como expressa (Morin, 1982), tanto um universo absolutamente determinista quanto um absolutamente aleatório são espaços pobres e deficientes, visto que o primeiro é incapaz de evoluir e o outro de nascer. Nessa direção, tem-se que uma gestão eficaz equilibra o determinismo e o caos. 
Dessa maneira, tendo por base os estudos sobre a teoria da complexidade e se pressupondo que os conflitos são inerentes às relações humanas, este estudo tratou do fenômeno no sentido de caracterizá-lo de modo diverso àquele que determina o paradigma dominante, ou seja, evitá-lo. Assim, o que se defende é que o conflito está alinhado àquilo que trata a teoria ora estudada, ao equilíbrio em desequilíbrio, já que a segurança de algo fechado coincide com a morte (Demo 2008).

Nessa direção, considera-se o conflito como complexo e essencial, concorda-se com Mariotti (2007), que expõe o pensamento complexo, cujo objetivo é de juntar coisas, pessoas e situações, a fim de que desse encontro surjam novas ideias, as quais proporcionam uma evolução constante. Destaca-se que o dissertado suscita outras inquietações e reflexões, entre elas, a influência de outros paradigmas que podem estar associados ao fenômeno do conflito. Nesse sentido, a proximidade com o construtivismo poderia instigar uma gama de possibilidades, em termos de agendas de investigação. Outra averiguação salutar é a empírica, na qual a proposição central se basearia em conhecer resultados de construtividade ou criatividade ocorridos a partir de situações de divergência. 


\section{Referências}

Bardin, L. (2011. Análise de conteúdo. Edições 70.

Boulding, K. E. (1962). Conflict and Defense: A General Theory. Harper \& Brothers.

Bourdieu, P. (1990). Coisas Ditas. São Paulo: Brasiliense.

Bourdieu, P. (2003). O campo científico. In R. Ortiz (Org.), Bordieu: sociologia (pp. 122-155). Olho d’Água.

Burrel, G, \& Morgan, G. (1979). Part 1: In Search of a Framework 1. Assumptions about the Nature of Social Science E 2. Assumptions about the Nature of Society. In G. Burrel \& G. Morgan (Orgs.), Sociological Paradigms and Organizational Analysis. Heinemann Educational Books.

Creswell, J. W. (2009). Research Design: Qualitative, Quantitative and Mixed Approaches (3a ed.). Sage Publications.

Demo, P. (1985). Metodologia Científica Em Ciências Sociais. Atlas.

Demo, P. (2008). Complexidade E Aprendizagem: A Dinâmica Não Linear Do Conhecimento (1a ed.). Atlas.

Descartes, R. (1979). Discurso Do Método. In René Descartes, Coleção Os Pensadores. Abril Cultural.

Faria, J. H. de. (2012). Dimensões da Matriz Epistemológica em Estudos em Administração: uma proposição. Anais do 36을 Encontro da Associação Nacional de Pós-Graduação e Pesquisa em Administração. Rio de Janeiro.

Fernandes Neto, Á. F. (2005). Gestão de Conflitos. Thesis 4, 1-16.

Fiorelli, J. O., Fiorelli, M. R., \& Malhadas Junior, M. J. O. (2008). Mediação e Solução de Conflitos: Teoria E Prática. Atlas.

Foulquié, P. (1949). A Dialética. Europa-América.

Gallo, G. (2013). Conflict Theory, Complexity and Systems Approach. Systems Research and Behavioral Science, 30, 156-175

Gerhardt, T. E., \& Silveira, D. T. (2009). Métodos de Pesquisa. Editora da UFRGS.

Grisales, R. M. (2011). El Debate Positivism-Constructivismo En Francia: Una Mirada Desde Las Ciências de La Gestión. In Formar En Administración: Por Una Nueva Fundamentación Filosófica. Fondo Editorial Universidad EAFIT.

Habermas, J. (2003). Direito E Democracia: Entre Facticidade E Validade (2a ed.). Tempo Brasileiro.

Hatchuel, A. (2005). Towards in Epistemology of Collective Action: Management Research as a Responsive and Actionable Discipline. European Management Review 2, 36-47.

Holland, J. (1995). Hidden Order: How Adaptation Builds Complexity. Helix Books.

Japiassu, H. (1991). Introdução Ao Pensamento Epistemológico. Francisco Alves.

Kuhn, T. S. (1962). The Structure of Scientific Revolutions. The University of Chicago Press.

Kuhn, T. S. (1989). A Tensão Essencial. Edições 70.

Le Moigne, J.-L. (2007). Les hypotheses fondatrices des épistémologies constructivistes. In J.-L. Le Moigne, Les épistémologies constructivistes (3ạ. ed., pp. 70-93). PUF.

Likert, R., \& Likert, J. G. (1980). Administração de Conflitos: Novas Abordagens. McGraw-Hill do Brasil. 
Mariotti, H. (2007). A Visão Do Conjunto. In H. Mariotti (Org.), Pensamento Complexo: Suas Aplicações À Liderança, À Aprendizagem E Ao Desenvolvimento Sustentável (pp. 83-108). Atlas.

McKibben, L. (2017). Conflict Management: Importance and Implications. British Journal of Nursing 26(2), 100-103.

Moore, C. W. (1998). O Processo de Mediação: Estratégias Práticas Para a Resolução de Conflitos (2a ed.). ArtMed.

Morgan, G. (2005). Paradigmas, Metáforas E Resoluções de Quebra-Cabeças Na Teoria Das Organizações. RAE -Revista de Administração de Empresas, 45(1), 58-71.

Morin, E. (1982). Ciência Com Consciência. Europa-América.

Morin, E. (1996). Problemas de Uma Epistemologia Complexa. In E. Morin (Org.), O Problema Epistemológico Da Complexidade (pp. 13-51). Europa-América.

Morin, E. (2011). Introdução Ao Pensamento Complexo. Porto Alegre: Sulina.

Morin, E., \& Le Moigne, J.-L. (1999). L'Intelligence de La Complexité. L’Harmattan.

Moscovici, F. (1997). Desenvolvimento Interpessoal: Treinamento Em Grupo (7ạ ed.). José Olympio.

Muszkat, M. E. (2005). Guia Prático de Mediação de Conflitos: Em Famílias e Organizações. Summus.

Parsons, T. (1967). Sugestões para um Tratado Sociológico da Teoria de Organização. In A. Etzioni (Ed.), Organizações Complexas. Atlas.

Popper, K. (1980). A Lógica Da Investigação Científica. In Coleção Os Pensadores. Abril Cultural.

Prigogine, I., \& Stengers, I. (1997). A Nova Aliança: Metamorfose Da Ciência (3a ed.). UnB.

Rahim, M. A. (2010). Managing Conflict in Organizations (4a ed.). Transaction Publishers.

Ramos, A. G. (1989). A Nova Ciência Das Organizações. FGV.

Robbins, S. P. (2005). Comportamento Organizacional (11a ed.). Pearson Prentice Hall.

Rocheblave-Spenlé, A.-M. (1974). Psicologia Do Conflito. Duas Cidades.

Sampaio, L. R. C., \& Braga Neto, A. (2017). O Que É Mediação de Conflitos. Brasiliense.

Saunders, M., Lewis, P., \& Thornhill, A. (2009). Research methods for business students (5a ed.). Pearson Education Limited.

Schenato, V. C. (2011). A Síntese Entre Objetividade E Subjetividade Mediada Pela Noção de Habitus Em Bourdieu. Perspectivas Sociais 1(1), 31-46.

Serva, M. R. (1992). O Paradigma Da Complexidade E a Análise Organizacional. RAE - Revista de Administração de Empresas 32(2), 26-35.

Serva, M. R., Dias, T., \& Alperstedt, G. D. (2010). Paradigma Da Complexidade e Teoria das Organizações: Uma Reflexão Epistemológica. Revista de Administração de Empresas 50(3), 276-287.

Triviños, A. N. S. (2012). Introdução à Pesquisa em Ciências Sociais. A pesquisa qualitativa em Educação. Atlas, 2012.

Wisinski, J. (1995). Como Resolver Conflitos No Trabalho. Campus. 